\title{
Vértice e base na pirâmide social da Tetralogia piauiense de Assis Brasil
}

Francigelda Ribeiro ${ }^{1}$

\begin{abstract}
RESUMO: Este artigo visa analisar os elementos sociais que sobressaem nos romances que compõem a Tetralogia piauiense de Assis Brasil. Tal análise respalda-se em algumas abordagens da crítica marxista e expõe, por meio do mapeamento cognitivo realizado pelo autor, os impasses gerados pela tensão entre totalidade e fragmentação no contexto narrado.

ABSTRACT: This article aims to analyze the most outstanding social elements found in the novels that compound Piauiense Tetralogy of Assis Brasil. Such analysis is grounded in some approaches of marxist criticism and reveals, through a cognitive mapping traced by the author, the impasses reached by the tension between totality and fragmentation in the context narrated.
\end{abstract}

PALAVRAS-CHAVE: Tetralogia piauiense; Crítica marxista; Mapeamento cognitivo; Totalidade e fragmentação.

KEYWORDS: Piauiense Tetralogy; Marxist criticism; Cognitive mapping; Totality and fragmentation.

Na série denominada Tetralogia piauiense - Beira rio beira vida (1965), A filha do meio-quilo (1966), O salto do cavalo cobridor (1968) e Pacamão (1969) -, orgânico projeto literário do escritor Assis Brasil, o teor simbólico dos romances ganha maior expressividade quando considerado o vínculo entre o estético e o contextual.

Conforme elucida Maria Elisa Cevasco (2003, p. 159-160), a crítica marxista tem "ensinado, entre outras coisas, que a matériaprima dos produtos culturais é o conteúdo social real, incluindo, é claro, as contradições estruturantes de nossa organização econômica e

1 Doutoranda em Literatura Brasileira pela Universidade Federal de Minas Gerais. E-mail: francigelda@yahoo.com.br. 
dos conflitos que ela determina em nossa vida política". Nesse sentido, vale destacar a relação entre os conflitos do universo simbólico da Tetralogia piauiense e o panorama socioeconômico da cidade de Parnaíba, no Piauí, na primeira metade do século XX, época na qual se situam os enredos. Denunciar o caráter anti-humano das relações reificadoras é um dos aspectos fulcrais que vincula tais romances ao debate intelectual da critica marxista.

Há na estrutura profunda das narrativas de Assis Brasil, uma representação da realidade que se aproxima, mutatis mutandis, da estética denominada de mapeamento cognitivo, nos termos propostos por Fredric Jameson, de acordo com ele:

Uma estética do mapeamento cognitivo - uma cultura política e pedagógica que busque dotar o sujeito individual de um sentido mais aguçado de seu lugar no sistema global - terá, necessariamente, que levar em conta essa dialética representacional extremamente complexa e inventar formas radicalmente novas para lhe fazer justiça (JAMESON, 2004, p. 79).

Pode-se admitir que o conteúdo exposto ao longo da Tetralogia se aproxima de tal proposta pelo que apresenta de oposição à fragmentação devastadora da essência humana, como também pela complexidade representacional que, politicamente direcionada, busca mapear um determinado contexto em sua totalidade, contribuindo para uma conscientização crítica diante das condições sociais determinadas pelas práticas capitalistas, a despeito das peculiaridades históricas daquele contexto. Vale ressaltar, neste prisma, que tanto os princípios teóricos de Jameson, quanto os estéticos de Assis Brasil estão mediados pela noção de totalidade que não se reduz ao acúmulo de todos os processos indistintamente, mas se trata de uma categoria que se reporta à compreensão de um fato como parte estrutural de um todo. Pensamento que Karel Kosik já havia afirmado ao argumentar que a "dialética da totalidade concreta não é um método que pretenda ingenuamente conhecer todos os aspectos [...] não é um método para 
captar e exaurir todos os [...] processos" (KOSIK, 1989, p. 35), mas a consciência de que todo fato só é devidamente compreendido se colocado em dimensão contextual.

Ademais, no caso específico da Tetralogia, o enfoque sociológico possibilita contemplá-la enquanto um exercício de mapeamento cognitivo, dado o expediente metodológico que oferece ao indivíduo uma dimensão crítica. Isso sem desconsiderar que os referenciais sobre os quais a obra está centrada são bem menos complexos do que aqueles caracterizadores do denominado capitalismo tardio.

Assis Brasil, transpondo à ficção a estrutura de classe da sociedade parnaibana - malgrado suas especificidades -, ressalta aspectos singulares em proporções universais e coloca, como cerne da estrutura representacional da Tetralogia piauiense, a complexidade do ser total frente às consequências trágicas da crescente fragmentação social.

Dotados de profundidade dialética, os romances focalizam, sob diversos ângulos, variadas formas da ação subjetiva diante dos conflitos sociais. Desse modo, é estabelecido um vínculo entre a realidade empírica com a qual dialogam os enredos e os romances enquanto produto artístico final. Estes mapeiam uma conjuntura social por meio das quais é exposto o modo de vida das camadas subalternas e é com a força representativa dessa exclusão que Assis Brasil constrói as personagens mais relevantes da sua Tetralogia.

Desvelando as contradições do fluxo econômico, da primeira metade do século XX, na cidade de Parnaíba, o autor transpõe, ao contexto interno da obra, a tensão entre os grupos sociais desfavorecidos e a ala beneficiada pelo desenvolvimento da cidade, à época. Se por um lado, tal desenvolvimento projetava o potencial empreendedor dos negociantes do cais de Beira rio beira vida: "o cais velho enriqueceu muita gente" (BRASIL, 1979, p. 104); por outro, minguava a esperança dos trabalhadores explorados. Os estivadores carregavam "o dia inteiro saca de arroz, fardo de algodão, quatro arroba de carnaúba de uma vez. Um ou outro, de vez em quando, não 
aguentava o rojão, ficava cuspindo sangue por aî” (BRASIL, 1979, p. 20). Era o preço da sobrevivência subjugada pelas injunções do sistema que, ulteriormente, ajustando-se às inovações tecnológicas, passavam a comprimi-los em meio à concorrência com as máquinas. Avançando à revelia das possibilidades dos trabalhadores locais, desumanizados em meio às crivadas relações de propriedade, o progresso da cidade se estabelecia unilateralmente, conforme se pode observar na voz das personagens de Beira rio beira vida: Luíza]

- Parnaíba está crescendo. [Nuno conversa com

- Só cresce lá pra cima, na parte plana. Estão até construindo uma Nova Parnaíba.

- Daqui a alguns anos como será tudo isso?

- Eu queria ver, eu queria ver.

- Eu também.

Nuno não voltou para ver a mudança - o desprezo pelo cais velho, lugar de perdição, cheio de rapariga. Os pés não esfarelavam mais os grãos derramados nas pedras que não encardiam, lavadas agora todos os dias, conservadas como uma jóia. Pranchas enormes ligavam os armazéns às barcas, os sacos iam escorregando, caindo no porão.

Os Moraes trouxeram a novidade - o algodão era chupado por uma máquina barulhenta, não preparavam mais os fardos. Os trabalhadores ficavam sem emprego e os pombos se mudaram por falta de comida (BRASIL, 1979, p. 118-119).

A questão ressaltada, na citação supra, trata-se de um reflexo do crescimento da indústria e do comércio que ocorreu na cidade de Parnaíba, até os anos cinquenta do século XX. O comércio local recebia e distribuía mercadorias via trajeto fluvial e marítimo, por meio de grandes companhias de navegação, dinamizando o avanço econômico da cidade que, no final da década de 1950, já exibia sinais de declínio financeiro.

Trazido ao universo dos romances, o ciclo econômico gerador de riqueza na cidade torna-se determinante na delineação contextual que molda os conflitos da obra. O posterior declínio no mercado internacional dos produtos extrativos adentra o tecido narrativo 
provocando a descapitalização de personagens empreendedoras que, sem o patrimônio de antes, passam a sobreviver de memórias. No romance Pacamão, Assis Brasil transpõe a ação devastadora desse declínio à trajetória empreendedora da personagem Bento Mavinier que, no período de crise, viu-se obrigado a manter a cera de carnaúba produzida em suas fazendas estocada nos armazéns do cais, sem mais ser embarcada. Conforme o romance,

Seu Bento [...] resolvera vender a [fazenda] Lagoa Escura, desde que a cera baixara de preço e os navios haviam passado a atracar só em Tutóia. Mas ia protelando, não sabia bem por que. baixinho.

- A cera este ano bem que podia dar mais - disse

Tentara arrendar a fazenda para José Laurindo, mas a ninharia que recebera no primeiro ano fazia até vergonha. Uma porcaria, que não pagava o trabalho de ir lá apanhar. O negócio de cera de carnaúba estava liquidado no Piauí, e com isso o Piauí estava liquidado. Seu pai fora mais feliz, vivera numa época que todos chamavam de "época das vacas gordas", quando a cera tinha um grande valor e o diabo dos americanos ainda não tinham inventado a cera sintética. Tudo isso, porque eles plantaram no solo deles e a cera não pegou.

- Depois da cera vem o café, e aí se acaba o Brasil - Seu Bento chutou uma casa de cupim na beira do caminho e procurou pensar nos propósitos daquela viagem (BRASIL, 1979, p. 425-426).

No real contexto parnaibano da época, a exportação da cera se enfraquecia diante da concorrência com o sucedâneo sintético dos produtos tropicais criados pelas indústrias internacionais. Vale ressaltar que, simultaneamente à fase ascensional da cidade de Parnaíba, expandiu-se uma considerável massa de excluídos: empregados do comércio, contramestres, marinheiros, remadores, estivadores, trabalhadores rurais, desempregados, dentre outros que compunham a base da pirâmide social - indivíduos que surgiam no élan das novas e complexas relações comerciais. Não são as marcas desse contexto meros reflexos na tessitura dos romances, mas o “momento histórico da emergência de suas possibilidades lingüísticas, 
[que possibilita] a função específico-situacional de sua estética" (JAMESON, 1992, p. 9). Assis Brasil mapeia, na reconstrução artística dessa conjuntura, o panorama social da cidade de forma a legitimar o papel de denúncia social da obra. A Tetralogia traz, enquanto projeto de denúncia, uma ótica tanto abrangente quanto complexa ao expressar o desejo de realização autêntica por parte das suas personagens mais marcantes, não obstante as sombras adversas do delineamento traçado pelas injunções capitalistas.

Em A filha do meio-quilo, por exemplo, os efeitos da segregação social ganham um momento peculiar na visão da personagem Lucília filha mais velha de Romualdo, segundo marido de Cota - resistente às coagulantes barreiras hierárquicas: "algo se impunha sob sua forma, para que ela não só justificasse algumas decepções, como em alguns momentos se sentisse com asas [...] para voar dali, desaparecer daquele buraco, onde as pessoas eram sempre hierarquizadas" (BRASIL, 1979, p. 164).

Fundada não somente sobre o vínculo econômico, a segregação social é fixada, no contexto da Tetralogia, também em critérios como origem familiar, tipo de trabalho, escolaridade e outros fatores que se tornam determinantes no movimento de dilatação e/ou contração das fronteiras estratificacionais. $\mathrm{Na}$ mesma esfera, sob considerável empenho realista, é possível entrever na obra - contribuindo para a tensão-mor dos romances, gerada pelo contraponto entre fragmentação e totalidade - o impasse premente advindo da relação entre centro urbano e periferia.

Nesse prisma, o critério da área residencial, dentro do sistema de estratificação, impõe inexoráveis determinações ao ser social figurado. Cremilda, personagem de Beira rio beira vida, por ser uma mulher dos prostíbulos ribeirinhos não consegue comprar uma casa no centro da cidade, embora contasse com uma quantia em dinheiro suficiente para tal. Consciente das implacáveis fronteiras, a personagem dialoga com a filha Luíza: 
- Eles disseram que meu dinheiro não dá.

- Pra quê?

- Pra comprar uma casa aqui na cidade. Sei que é mentira, eles não querem é me vender. Um ainda disse: "Mesmo a senhora não pode se mudar pra cidade". Foi o que um deles disse, Luíza, e os outros acharam graça (BRASIL, 1979, p. 41).

Evidenciam-se, assim, as demarcações de uma mentalidade social que termina por gerar, na linha determinante do status quo, os epiciclos dos espoliados: dos explorados do cais (Beira rio beira vida), dos barraqueiros do mercado (A filha do meio-quilo), dos agregados de fazenda ( $O$ salto do cavalo cobridor), dos empregados de baixa renda (Pacamão). Em momentos de maior angústia, a miséria parece minguar a esperança destes. No cais de Beira rio beira vida: "todos sabiam e aceitavam, a vida era aquela, botar os passos no rumo e pronto. Eles nasceram na cidade para dar esmolas, elas nasceram no cais para receber" (BRASIL, 1979, p. 54). Um contraste com essa barreira, porém, insurge com a personagem Mundoca, moça ensimesmada e com traços destoantes dos gestos lascivos da avó, Cremilda, e da mãe, Luíza. Mundoca optou por outra rota vital, não menos explorada, não menos sofrida, mas que rompia com a rotina de prostituição de suas antepassadas. Aceitou o emprego oferecido pela madrinha na loja de tecidos do marido e passou a vender sua força de trabalho aos que detinham o monopólio do comércio. Contudo, trabalhar na cidade não significou adentrar suas estruturas, cujos traços a impressionavam: "[...] quanto carro na praça da Graça [...] - Todo mundo anda bem vestido. [...] - As moças são bonitas” (BRASIL, 1979, p. 51-52).

Em A filha do meio-quilo, a tensão entre cidade e subúrbio pode ser percebida de forma contundente, por meio da ação de Cota que, buscando transcender ao discurso da setorização sociogeográfica, reagiu implacavelmente contra a estrutura reacionária dominante.

Cota conseguiu, após vasta peregrinação seu primeiro emprego, deixando a barraca que o pai tinha no mercado da cidade. Ela namorou Godofredo, gerente da loja na qual trabalhava. Godofredo morava no 
nascente bairro da Nova Parnaíba, que constituía mais um fio representativo da distância mantida entre as classes sociais. Confessando-se com padre Gonçalo, anos mais tarde, Cota desabafa:

Não pense que Godofredo armou ciladas para mim. Não, fui espontaneamente para sua casa, para uma das melhores casas da Nova Parnaíba. Estavam construindo ali um bairro de luxo, "para a elite", diziam. E que belas casas, se tornaram inveja para muitos. Nem todos poderiam ir para aquelas bandas - os condenados, os que haviam nascido com uma marca. Godofredo morava lá. A principio fui levada pela curiosidade; mais tarde pelo meu fascínio (cada vez mais acentuado) em enfrentar os que me conheciam mal. Eu, a filha do meio quilo, freqüentando a Nova Parnaíba, passando dias e dias numa casa de luxo (BRASIL, 1979, p. 229).

O centro da cidade e o bairro da Nova Parnaíba - onde estava "a casa do Prefeito, a casa dos Moraes, a bela casa do padre. [...] não apenas os ricos; também os que têm certa posição social” (BRASIL, 1979, p. 232) - são os loci privilegiados da burguesia figurada. Cota conseguiu transitar pelos espaços demarcados por uma classe que excluía a sua. Em Pacamão, por exemplo, é ressaltado o fato de os membros da familia Mavinier, mesmo depois da falência econômica, tanto se considerarem quanto continuarem detentores de grande prestígio social, cujo reconhecimento é difundido, indiscriminadamente, por toda a sociedade. $\mathrm{Na}$ imagem construída de membros conspícuos da elite, não abdicavam dos seus pedestais de superioridade. Desse modo, quando Nazinha, filha do casal Mavinier, apaixonou-se por Leandro, rapaz de origem humilde, um carteiro habitante do cais, a imponência dos pais surgiu como interdito cabal ao relacionamento dos dois:

Resolvemos logo que Leandro não gostava de Nazinha, que tudo aquilo era farsa, suas atitudes denunciavam apenas interesse, interesse baixo. [...]

- Você não pode gostar desse homem, Nazinha.

- Por que não? Por que não?

- Não é do nosso meio, é um pobre coitado, sem eira nem beira.

- [...] Leandro é a única pessoa que me dá atenção (BRASIL, 1979, p. 392-393). 
Como um brado: "a nossa posição [...] [tem] de ser mantida" (BRASIL, 1979, p. 412) - ressoava a voz de dona Raimunda, avó de Nazinha. O pai, Bento Mavinier, levou a rejeição ao extremo, aderindo à barbárie como forma de manutenção da ordem, comunicou sua decisão à esposa:

- Zuleica, vamos dar um sumiço no Leandro, eu vi o cabra de perto, é um sem-vergonha, um calculista. E ainda por cima não tem educação. Você já pensou esse sujeito na sala de nossa casa, proseando e palitando os dentes? Não, não. Mesmo que Nazinha nos odeie, mesmo que se mate, sei lá, ou que seja verdade que espera um filho daquele cachorro, vamos dar um sumiço nele.

[...]

- Nazinha não pode se casar com esse homem - foi o que respondi (BRASIL, 1979, p. 395-396).

Leandro havia combinado com Nazinha que ela engravidaria, a fim de forçar que a família dela aceitasse o casamento. O plano contava com a concessão dos pais que, obviamente, não admitiriam a filha desonrada. Todavia a reação foi dar cabo da vida do rapaz e aprisionar Nazinha durante a gravidez, julgando o fato menos constrangedor do que vê-la casada com um carteiro.

A Tetralogia denuncia, pois, as práticas que fazem "da dignidade pessoal um simples valor de troca e, no lugar de um sem-número de liberdades, [colocam] a liberdade única, sem escrúpulos, do comércio" (MARX; ENGELS, 1998, p. 7). Esse caráter deformador das relações no sistema capitalista suprime os valores humanos por força da exploração torturante. A denúncia dessas deformações sociais nas relações humanas, em suas proporções mais profundas, torna-se o leitmotiv da Tetralogia piauiense e, uma vez que remete aos processos de superação dos antagonismos, contempla questões que, consequentemente, conferem atualidade à obra. Na Tetralogia, Assis Brasil figura situações que focalizam o mundo do trabalho alienado e seus reflexos na trajetória das personagens: desígnio que funciona como mais um elemento legitimador da contiguidade entre a obra e as reflexões da estética marxista. 
Nessa esfera, destaca-se o percurso de personagens como Mundoca e Jessé, em Beira rio beira vida, e Cota, em A filha do meioquilo. Almejando superar as adversidades sociais por meio do trabalho, tais personagens buscam construir uma identidade à revelia dos dispositivos meramente mercadológicos aos quais estão submetidos enquanto trabalhadores desapropriados. Não obstante estigmatizados por suas condições sociais - Mundoca enquanto filha de prostituta; Jessé como operário do pequeno armazém de arroz de Cremilda e Cota enquanto filha de Nhôzinho (o meio-quilo), um barraqueiro do mercado são personagens que lutam por uma forma de trabalho que lhes permita novas possibilidades existenciais. Ousando a inserção social, suas práticas representam tentativas de emancipação, marca de resistência contra os discursos reacionários.

Jessé, desde pequeno cultivava o sonho de ser um grande empreendedor, quando deixasse o armazém de Cremilda, "viajaria num navio dourado. E quando crescesse iria embora num navio de verdade, para bem longe" (BRASIL, 1979, p. 31). Os sonhos o enlevavam e projetavam um futuro de negócios, Jessé voava nas asas de ingênuas ambições, cujas expectativas o conduziam para longe de sua rotina, no mais das vezes, pouco feliz. Até sonhou ficar rico - "Pensa que estou brincando? Ele dizia, 'estou ganhando o meu dinheiro, estou ganhando o meu dinheiro" (BRASIL, 1979, p. 110) - e ainda quis estudar, mas Cremilda, de imediato, recriminou-o diante dos outros trabalhadores do armazém de arroz. Não estudou, não se tornou o negociante que sonhara ser, nem se casou com Luiza. Seus sonhos feneceram na lida ingreme dos carregamentos das barcas que subiam e desciam o rio Parnaíba, "conheceu todas as embarcações - as de vela e as de remo. Ia nos grandes navios, enfeitados de bandeiras, e voltava nas barcas lentas puxadas pelos ombros dos homens" (BRASIL, 1979, p. 70). Seguia sua rotina na condução das cargas, até o dia em que foi abrasado por fardos de algodão em meio às chamas e ao desejo de transcendência. 
Mundoca, por seu turno, rompeu com a vida de prostituição comum às suas antepassadas, a mãe lhe dizia: “- Eu cumpria a sina, Mundoca. [...] Poucos caçoaram no cais, mas caçoaram, 'quem é o pai, Luíza? Quem é o pai, ou você não sabe?" (BRASIL, 1979, p. 56-57). Tal sina não ladrilhou o percurso de Mundoca, embora o emprego na cidade não tenha alterado sua condição de miséria. Morava com a mãe que envelhecida já não podia competir com as concorrentes dos meretrícios ribeirinhos. Na voz da mãe, Luíza, a repetição da vida minguada.

Comprei uma cordinha de peixe hoje, Mundoca. É só botar pra ferver. Aquele dinheiro que você me deu foi bem aproveitado [...] Comprei uma caixa de fósforo, uma penca de banana e meio litro de querosene. Seu Mundico me deu um punhado de farinha, não foi esmola, não. [...] Fiquei de olho comprido foi na rapadura que seu Mundico recebeu também. Como não me deu, não disse nada. Se você ainda tem dinheiro do mês, Mundoca, compre uma banda de rapadura pra gente aproveitar essa farinha (BRASIL, 1979, p. 92-93).

Os sonhos amordaçados, o futuro coibido na extensão do cais abrigo e labéu -, vidas sempre oprimidas pelo sistema dominante que lhes retraía para aquém da totalidade e dignidade humanas, colocandoas às margens da existência - na beira do rio, na beira da vida. No cais, a complexidade humana transmutava-se em subsistência; sob o signo da dominação, vidas eram manipuladas a baixo custo. Mundoca acabou se tornando vítima da auto-alienação, apesar do desejo de transcendência que, débil, resultou sem alterações sensíveis.

Quanto corte de fazenda tem ficado aí no baú esperando por linha [...] Por mim a gente voltava lá pro Igarapé.

Você sabe, Mundoca, que preveni que iam falar - a comadre até ia jogar na cara da gente o favor feito. Você fica lá de enfeite: essa aí é a filha da Luíza, não se lembra? Aquela?

Não quero sacrificio de ninguém, já disse. Por mim a gente voltava lá pro igarapé. [...] Você se lembra, nossa chegada em casa era como uma festa, carregada de coisa, peixe, caranguejo [...] A gente nem reparava que só comia 
uma vez por dia, você sabe, Mundoca. O que sobrava sempre sobrava alguma coisa - a gente vendia pra comprar querosene, farinha, fumo e rapadura. Agora é isso, essa danação de falatório, de alegação - o dinheiro dela [da madrinha] não é igual ao nosso? E não é tanto assim - desde quando a gente não pode comprar um tamanco? Uma panela nova? (BRASIL, 1979, p. 84).

Mesmo contra as expectativas sociais do contexto, Mundoca rompeu com o trágico destino da prostituição que subjugara sua ascendência. Na janela do seu barraco, embalada pela fumaça do cachimbo, assistia ao futuro: o mesmo barraco, as mesmas necessidades, contudo parecia satisfatório não pertencer ao mesmo ciclo de dominação no qual se confinaram as também solitárias mulheres de sua familia.

Em A filha do meio-quilo, na trajetória da personagem Cota, há o movimento mais decisivo de luta contra a reificação dentro do universo da Tetralogia, porque em oposição constante aos discursos opressores, como também por ter conseguido êxito na tentativa de ascensão social. Subversiva, afrontou valores sedimentados e, quando decidida conseguiu emprego na Casa-Duíno Representações. Mesmo perdendo tal emprego - por intervenção dos conservadores da cidade, quando do seu namoro com o gerente da loja - seu futuro emprego na Loja de Tomás, bem como seu casamento com o mesmo, assegurou-lhe, a um tempo, realização afetiva e profissional.

Os episódios narrados ao longo da Tetralogia revelam a profundidade com que Assis Brasil capta, do real, arraigadas problemáticas, denunciando-as no tecido composto. Tal aspecto, caracterizador da arte realista, remete-se à função cognitiva e sociológica da arte. Conforme esclareceu o marxista Sánchez Vázquez (1978, p. 36), a autêntica arte realista apresenta a realidade em três níveis distintos: como realidade exterior (no caso da Tetralogia, a cidade de Parnaíba com seu conteúdo empírico), a partir da qual se cria uma nova realidade (Tetralogia piauiense) que reflete, essencialmente, uma realidade humana (situação representada no universo criado e sua 
relação com a realidade factual). Trata-se de um processo que partindo do concreto vai para o abstrato, mas volta a dialogar com aquele, à medida que expõe o movimento de superação de lacunas sociais, conservando a inclinação da arte à utopia.

Assis Brasil faz emergir, ao longo da obra, o mundo do oprimido desvalorizado pelos discursos oficiais. Partindo de um contexto histórico de grande efervescência econômica, confere, literariamente, voz às minorias sempre niveladas ao valor mercadológico no universo burguês. A irrupção de personagens (Mundoca, Jessé, Cota, Matias, Darcy e Nazinha, ponderando suas especificidades) que se chocam, de algum modo, contra a passividade social possibilita uma relação de confronto entre o discurso questionador que se estende ao longo das narrativas e as formas de alienação da sociedade capitalista - o mundo convencional e vazio a que se referiu o Lukács da primeira fase -, a despeito dos costumes e tendências de teor feudalistas ainda operantes nela. Sobressai, com efeito, no plano narrativo, a questão da alteridade: o espaço de construção do outro como um dos vetores da visão totalizadora e, portanto, dialética que subjaz à obra. Conforme predica Sartre, escrever é "recorrer à consciência de outrem para se fazer reconhecer como essencial à totalidade do ser" (1993, p. 49).

$\mathrm{Na}$ Tetralogia, o caráter relacional entre as classes constitui o campo cêntrico dos eventos narrados, permitindo uma ampla exposição das assimetrias classistas. O autor, trazendo à composição, as tensões representacionais do quadro histórico da época, capta aspectos viscerais dessa realidade humana, dissipando-lhe "o véu de suas mistificações" - função da arte realista, conforme escreveu Sánchez Vázquez (1978, p. 38). Tal procedimento conduz, inelutavelmente, o leitor a um sentimento de indignação para com as camadas conservadoras e hostis que tendem a desvanecer os discursos que se desprendem de ser-lhe subserviente. Situação perceptivel quando são expostas, por assim dizer, as perseguições contra as personagens Mundoca e Cota em suas iniciativas. A procedência de Mundoca afastava as freguesas que já não escolhiam os tecidos com a mesma 
satisfação de outrora. Seu Jacinto, o dono da loja, começou a demonstrar os primeiros sinais de preocupação com os negócios, apesar de estar, frequentemente, assediando a afilhada. Os comentários principiavam-lhe certa inquietação: “- Como é, Jacinto, você abriu uma casa de caridade?" (BRASIL, 1979, p. 52). A esposa divulgava a caridade, impedindo-o de desfazer o ato. "Ele tinha vontade [...] de afastar aquela criatura esquisita da loja, mas a mulher continuava a espalhar que era por caridade, Mundoca tinha mãe para sustentar, eram umas desvalidadas" (BRASIL, 1979, p. 52). Ao final de toda perseguição, Mundoca "foi transferida para o armazém nos fundos da loja - conferia as peças de fazenda, outras mercadorias, arrumava as prateleiras, espanava, ou ficava apenas a olhar os ratinhos que saiam dos buracos" (BRASIL, 1979, p. 52).

Quando Cota, em A filha do meio-quilo, assumiu um percurso de descentralização, subvertendo os tabus patriarcais e mantenedores da tradição feminina servil, a cidade se levantou em reação hostil, indignando-se com o modo incongruente da moça, “(...) formou-se uma comissão, para ir à firma Casa-Duíno Representações, em nome da dignidade ultrajada da cidade, contra aquela união de um seu funcionário com uma filha da terra" (BRASIL, 1979, p. 218). Julgavam que Cota se tornara amante de um homem casado, já que ele não a pedira em casamento. A comissão, apesar de verificar por meio dos documentos pessoais de Godofredo que ele era solteiro, argumentou que o escândalo não repercutiria menor, pois as viagens que faziam juntos à praia de Amarração era uma afronta à Igreja e às famílias que visitavam o local. Os componentes da comissão esperaram o retorno de Dr. Celso, proprietário da loja, que estava viajando. "Discursaram perante ele, não mais na loja, para evitar a presença de Godofredo, mas em sua casa avarandada na travessa do Bosson" (BRASIL, 1979, p. 219-220). O resultado foi Godofredo transferido e Cota desempregada. Contudo, a mesma comunidade a recebe quando ela ressurge com novo emprego e ao lado de um dos rapazes mais cobiçados pelas moças da cidade. 
Em $O$ salto do cavalo cobridor, embora seja exposto o universo rural, moldurado por comodidade e naturalização das circunstâncias sociais, o autor lança luz sobre situações de superação despontadas, sobretudo no personagem Matias.

No romance, o casal Zita e Inácio - personagens centrais do romance e agregados da fazenda Frecheira da Lama - cuidava da fazenda com grande zelo, "aquilo tudo era para Inação como se fosse seu, parte até de seu próprio corpo, e quando se afastava, mesmo pela vizinhança, voltava logo, sofrido pela saudade" (BRASIL, 1979, p. 272). Tamanha dedicação era compensada pela amizade que o casal julgava ter dos patrões. Inácio conversava, "como se fosse igual a eles e tivesse as mesmas letras. E caprichava nos ditos e fatos para não parecer um homem atrasado" (BRASIL, 1979, p. 277). Envolto pela pseudoparidade, o casal de agregados - presa fácil da exploração e vítima da dominação latifundiária - só se alimentava dignamente nas ocasiões da presença dos patrões. Período em que "todos os vizinhos pobres recebiam um pouco mais de ajuda da mulher de Inação" (BRASIL, 1979, p. 274). Era festivo diferenciar um pouco, durante a estada dos patrões, a comida parca que os alentava para a lida diária. Ao retornar para Parnaíba, dona Candinha alertava:

- Olhe aqui, Zita: não passe necessidade, ouviu? Quando tiver vontade de comer uma galinha, um capadinho, pode matar sem susto, não passe privação, gente, o Gervásio não se incomoda.

Mas Zita sabia que aquele oferecimento todo era só da boca pra fora, pois o marido de dona Candinha era muito exigente com as contas do Inação. E Zita respeitava a economia e as contas do marido, e passava meses e meses comendo macaxeira, feijão com arroz, angu de milho e berinjela frita. Aí Inação resolvia ir caçar e enchia a despensa de tudo quanto era bicho miúdo do mato. Zita salgava as marrecas e os preás, e tinham melhor rancho por algumas semanas - isso muito tempo depois que ela se acostumou a comer caça (BRASIL, 1979, p. 275). 
Assumindo o ethos de uma organização social feudalizante, as personagens, dadas as forças atávicas, entregam-se à adaptação de um mundo estagnado e assim seguem, garantindo, ao menos, as condições mínimas de sobrevivência. O olhar servil de Inácio e Zita se contrapõe à visão capitalista dos proprietários, o que constitui um campo propício para a figuração do universo reificado, em cuja plataforma manifesta-se a degradação dos vínculos humanos.

O deslocamento da ótica narrativa da cidade para o campo, em $O$ salto do cavalo cobridor, concorre, ademais, para uma representação mais ampla das relações sociais no conjunto da obra. Assis Brasil dá expressão à hostilidade a que o homem agrário, especificamente o analfabeto e destituído do desejo de mobilidade social, está submetido. Entretanto, encontra-se em Matias - "o mais conhecido vendedorambulante da região. Se intitulava de caixeiro-viajante e não relaxava o chapéu de chile" (BRASIL, 1979, p. 284) - uma demonstração de maior lucidez acerca das injustiças sociais. Por meio do seu discurso, são questionados problemas que, frontalmente, atingem o universo do trabalhador rural, como a Reforma Agrária, por exemplo.

Matias estava sempre comentando a situação das terras abandonadas, sem serventia. Quando tinha jeito, voltava ao assunto, e Inação tinha que escutar:

- Compadre, você aí da janela [do trem] vê esse mundo de terra todo?

- Estou vendo.

$[\ldots]$

- São terras do governo. [...] É um despropósito, Inação, quantas pessoas necessitando, pedindo um palmo de terra para plantar. [...] Essa terra toda do Piauí, do Ceará e até do Maranhão, pertence a muito pouca gente. Gente gangenta, com a mão fechada assim para os outros. Pobre na unha deles passa o diabo.

- Onde soube disso tudo, Matias?

- Ora, nas minhas viagens, conversando com um ou outro, conversando com gente de cabeça, que entende de política. [...] Quando fui aprender a ler lá em Marruás, no ano retrasado, tinha uma professora que vivia falando nessa questão de terra. [...] Dizia que tudo tinha que ser repartido, pra quem quisesse plantar - cada família podia ter seu pedaço de terra. Acho que isso era o que tinha de ser mesmo o certo (BRASIL, 1979, p. 307-308). 
Matias, revelando certo grau de consciência critica diante da realidade social e humana na qual está inserido, não comum à época figurada, sobreleva-se à média das demais personagens que, subsumidas ao discurso conformista, aderiam à passividade dos hábitos do indivíduo rural comum, que lança às forças sobrenaturais a responsabilidade pelas agruras que lhe coíbem as aspirações. A visão desmistificadora de Matias traz os problemas vivenciados para o plano da imanência social, vinculando-os às condições históricas em detrimento de quaisquer causas supra-humanas. Trata-se de um contraponto à transcendência pela vertente da religiosidade simplória que representa a nulidade da ação humana, ao passo que concorre para a naturalização dos discursos mantenedores da opressão. A alienação religiosa, conforme assinala Marx, é gerada pela alienação econômica que destitui as aspirações do indivíduo. Sentindo-se lesado, este projeta seus anseios para uma realidade de valores eternos, como fuga da deformação ocasionada pelo sistema explorador mantido pelos detentores dos meios de produção. Nesse sentido, não é aleatoriamente que o autor desloca a massa ficcional para a ambientação agrária, assim seu ideal de denúncia atinge em maior proporção a complexidade na qual se configuram as relações de exploração.

A associação do destino particular de algumas personagens à trajetória social de um sem-número de indivíduos faz emergir à superficie do texto o hiato entre o sujeito e o mundo. Superar essa cisão - alienante da própria condição humana - é o que coloca em cena o teor do desejo de totalidade. Com efeito, o ideal de totalidade não se reduz ao limite de uma consciência única, pois alude sempre ao universal. Ademais, não se pode olvidar de que se trata de uma categoria regida por princípios dialéticos: "a totalidade sem contradições é vazia e inerte, as contradições fora da totalidade são formais e arbitrárias" (KOSIK, 1989, p. 51). Na Tetralogia, elite e subalternos (vértice e base) são tematizados como parte de um todo que "não pode ser petrificado na abstração situada por cima das partes, visto que o todo se cria a si mesmo na interação das partes" (KOSIK, 1989, p. 42). Assim, os 
acontecimentos são ressaltados conjunturalmente. Entender o destino das personagens centrais de modo satisfatório exige que se supere uma visão solipsista e psicológica, reconhecendo que "nada existe que não seja social e histórico" (JAMESON, 1992, p. 18).

Se considerados no conjunto, os romances da Tetralogia - como uma produção, inconsutilmente inter-relacionada, embora a leitura dos romances possa ser feita isoladamente - será possível atingir o sentido complexo da função desalienante efetivada na estratégia do mapeamento realizado pelo autor. Opondo-se, criticamente, ao caráter anti-humano do capitalismo, são criadas as condições que põem em evidência a já assinalada tensão central da obra: fragmentação versus totalidade, da qual derivam os demais impasses. Tensão que vai se constituindo, à medida que é desnudada a miséria das massas populares, de cujo interior ainda emana a resistência de personagens que lutam, sem deus ex machina que as auxilie, contra a ideologia hegemônica.

O mapeamento do contexto da cidade de Parnaíba, contemplando tanto os efeitos da fase áurea da sua economia quanto do colapso que já se fazia sentir, focaliza os diversos espaços que atuam na composição do ser social, para fim de uma representação mais abrangente de um sistema matizado por conflitos ainda frequentes nos dias atuais.

Como destacou o próprio Jameson, há entre os diversos estágios do capitalismo uma relação de continuidade, em cujo sequenciamento sobrevivem muitos enclaves do período anterior, rejeitando, portanto, a idéia de que o período atual seja concebido como uma estrutura independente dos períodos precedentes. Afinal, não obstante as mutações pelas quais passou o capitalismo, mantém-se estável "o fluxo constante de mercadorias e o sistema que sustenta esse fluxo" (CEVASCO, 2003, p. 160).

Assis Brasil, expondo as contradições do ser social, constrói eventos em uma perspectiva coerente de humanização. Rejeitando as práticas reificadoras, denuncia os reflexos da exploração capitalista, 
bem como os desdobramentos ideológicos que concorrem para a nulidade das potencialidades autenticamente humanas.

\section{Referências bibliográficas}

BRASIL, Assis. Tetralogia piauiense. Rio de Janeiro: Nórdica, 1979.

CEVASCO, Maria Elisa. A utilidade da critica cultural marxista. In: GALVÃO, Andréia, et alii (Org.). Marxismo e ciências humanas. São Paulo: Xamã, 2003.

JAMESON, Fredric. $O$ inconsciente politico: a narrativa como ato socialmente simbólico. São Paulo: Ática, 1992.

- Pós-modernismo: a lógica cultural do capitalismo tardio. São Paulo: Ática, 2004.

KOSIK, Karel. Dialética do concreto. Rio de Janeiro: Paz e Terra, 1989.

MARX, Karl; ENGELS, Friedrich. Manifesto do Partido Comunista. São Paulo: Cortez, 1998.

SARTRE, Jean-Paul. Que é a literatura? São Paulo: Ática, 1993.

SÁNCHEZ VÁZQUEZ, Adolfo. As idéias estéticas de Marx. Rio de Janeiro: Paz e Terra, 1978. 